\title{
Serratus Anterior Stretch: A Novel Intervention and Its Effect on the Shoulder Range of Motion
}

\author{
Keramat Ullah Keramat and Mohammad Naveed Babar
}

\begin{abstract}
Context: Serratus anterior tightness is associated with scapular dyskinesis and overall shoulder dysfunction, which affects the range of motion. The most effective intervention to stretch the serratus anterior is unknown. Objective: To evaluate the effect of a therapistadministered novel serratus anterior stretch (SAS) on shoulder range of motion. Method: This study recruited 30 healthy subjects of age 21.20 (1.69) years, height $1.65(0.11) \mathrm{m}$, and weight $60.90(10.36) \mathrm{kg}$ in equal ratio of males and females who scored 1 or 2 on the shoulder mobility test of functional movement screening. A single intervention of a novel SAS was applied to the shoulder. Outcome variables before and after the SAS included the following: shoulder ROM (flexion, abduction, internal rotation, and external rotation) and functional movements of reaching up behind the back and reaching down behind the neck. Results: A paired $t$ test was used to analyze the data. Following the acute SAS intervention, all shoulder ROM improved significantly $(P<.000)$. The change in internal rotation was $6.00^{\circ}\left(7.47^{\circ}\right)$, external rotation was $5.66^{\circ}\left(9.35^{\circ}\right)$, abduction was $13.50^{\circ}\left(11.82^{\circ}\right)$, flexion was $20^{\circ}\left(13.33^{\circ}\right)$, reaching up behind the back was $5.10(2.21) \mathrm{cm}$, and reaching down behind the neck was $5.41(2.89) \mathrm{cm}$. The most marked improvement was in reaching up behind the back $(24.48 \%)$ and reaching down behind the neck $(22.78 \%)$. A very large effect size (>1) was observed across most of the variables. Conclusion: An acute SAS intervention improves shoulder mobility in healthy individuals. It is recommended for the trial on the prevention and rehabilitation of shoulder pathologies with restriction in shoulder mobility.
\end{abstract}

Keywords: shoulder, manual therapy intervention, posterior capsular tightness, pragmatic posterior capsular stretch

The serratus anterior (SA) originates from the first to eighth ribs and their intercostal spaces. Three divisions of the muscle are identified. The first division originates from the first and second ribs and their intercostal space and inserts on the costal aspect of the superior angle of the scapula. The second division is formed by 3 digitations from the second, third, and fourth ribs and their adjoining septum and inserts on the costal aspects of the medial border of the scapula. The third division is the longest and strongest and is formed by the lower 4 or 5 digitations from the fourth to eighth ribs. It inserts on the inferior angle of the scapula. ${ }^{1}$ The divisions of SA are theorized to be different functionally: the upper is more active in protraction of scapula, and the lower division may assist in depression along with abduction and protraction of the scapula. ${ }^{2}$ The lower division is reported with maximum electromyographic activity in resisted tasks above $120^{\circ}$ of overhead movement in all planes. ${ }^{1,2}$ Recognition of the 3 parts and their relative role is important for exercise programs and stretching for the prevention and rehabilitation of shoulder pathologies.

The 3 divisions of the SA and the upper and lower parts of the trapezius form a force couple, which affords dynamic stability to the scapula during the movement of the arm. Movements in different planes require varying activity of the components of the SA and trapezius. ${ }^{1,2}$ An imbalance between the parts of the SA and trapezius may lead to scapular dyskinesis., ${ }^{3,4}$ Uhl et $\mathrm{al}^{4}$ reported 3 types of abnormal positions of the scapula corresponding to the 3 divisions of the SA and the imbalance between the SA and trapezius. The length and strength of the SA are strongly related to posterior shoulder tightness and forward scapular posture. ${ }^{5}$ Although, these changes are asymptomatic initially but can lead

Keramat is with the HHIRS, Mansehra, Pakistan. Babar is with the Isra Institute of Rehabailation Sciences, Isra University, Islamabad, Pakistan. Keramat (karamatjee@yahoo.com, karamatjee@gmail.com) is corresponding author. to shoulder pathology. Prospective studies have reported an increased prevalence of shoulder pain among athletes with scapular dyskinesis. $^{6}$

Exercise programs are recommended to manage the imbalance between the division of the trapezius and SA. ${ }^{2,7}$ Various exercises, such as shoulder press, push-up, press-up, prone abduction, and prone flexion, with high and low intensities elicit different EMG activity in the division of the trapezius and SA. ${ }^{2}$ Recognition of these aspects may be of clinical importance.

Overhead repeated shoulder movements, scapular dyskinesis, and postural anomalies are linked with SA flexibility and its dysfunction. ${ }^{8,9}$ A therapist-administered stretch to the lower and middle division might help in the restoration of the length and improvement of SA function, which is hypothesized to affect the shoulder range of motion. The purpose of this research was, therefore, to evaluate the effects of a novel and specific SA (SAS [serratus anterior stretch]) stretch on the range of motion of the shoulder joint in healthy subjects.

\section{Methodology}

\section{Study Design}

A single group quasi-experimental design was used to test the novel intervention of SAS. The effects were measured in terms of change from the baseline scores after submitting the subjects to intervention. A convenient sample of 30 undergraduate healthy students fulfilling the inclusion criteria were recruited. A sample size of 30 was deemed appropriate after a pilot trial on 5 healthy subjects, which produced a meaningful difference of a $15^{\circ}$ change in abduction and a $3-\mathrm{cm}$ difference in reaching up behind the back (RUBTB), using SD estimates from previous studies. ${ }^{10}$ Healthy volunteers with restricted ROM were appropriate, as the novel intervention aimed to improve the shoulder ROM by improving scapular mobility primarily. Subjects with shoulder pathology may 
have pain and strength deficits, which may not truly measure the effects of an SAS. The inclusion criteria were scores of grade 1 or grade 2 on the shoulder mobility test of functional movement screening $\left(\mathrm{FMS}^{\mathrm{TM}}\right) .{ }^{11}$ Both grades indicate restriction in functional movement and shoulder ROM. Subjects with any pathology of the shoulder and with scores of grade 0 and grade 3 (no restriction in shoulder mobility) on the same scale were excluded. Subjects with grade 0 were not included, as the distance between the 2 bony prominences in each hand cannot be measured. The study design was approved by the research and ethics committee of the Helping Hand Institute of Rehabilitation Center, and the Board of Advanced Study of Isra University, Islamabad. An approved informed consent form was signed by each subject. Before commencement, the trial was registered on clinicaltrials.gov (NCT04242888), and the current report represents one of the 5 arms of the clinical trial.

\section{Participants}

The mean (SD) for the age, weight, and height of the subjects was 21.20 (1.69) years, $60.90(10.36) \mathrm{kg}$, and $1.65(0.11) \mathrm{m}$, respectively. The subjects were 15 males and 15 females, both recreationally active. Most male participants (33\%) were either playing cricket or volleyball or both. Six females were not involved in playing overhead sports, but would regularly use their shoulders in overhead activities during household chores.

\section{Data Collection and Instruments}

All participants were evaluated on their shoulder mobility to identify individuals with grade 1 and 2 results. First, hand length was measured from the distal wrist crease to the tip of the third digit. Then, the participant was instructed to reach down behind the neck with one hand in a fist position and reach up behind the back with the other hand in a fist as far as possible. The distance between the 2 hands was measured. Grade 1 and 2 would indicate restricted shoulder mobility and ROM. ${ }^{11}$ Functional movement screening has been reported with good interrater and intrarater reliability and validity. ${ }^{12}$

A total of 108 subjects were screened. Seventy-eight subjects were excluded. Five excluded subjects ( 4 males and 1 female) were of grade 0 , and the remaining 73 subjects were of grade 3 on the functional movement screening shoulder mobility test.

A digital inclinometer (clinometer application) installed on a Samsung Note 8 (Samsung Electronics, Pakistan) was used for measuring the shoulder active ROM. The use of a digital inclinometer was validated for measuring the internal and external rotation of Cronbach alpha values of .95 and .94 , respectively. ${ }^{13}$ It has been recommended for the measurement of shoulder range of motion, and the mean level of bias is reported up to $3.4^{\circ}$ compared with a gold standard. ${ }^{14}$ The phone was strapped to the wrist, and the reading on the inclinometer was set to 0 at $90^{\circ}$ abduction of the shoulder in a forearm supination on a Bobath's plinth for internal rotation and external rotation. Measurements for abduction, flexion, RUBTB, and reaching down behind the neck (RDBTN) were taken in the standing position. Four trained undergraduate students took the measurements before and after the intervention under the supervision of a senior physiotherapist. The principal investigator was blind during the selection of subjects and data collection process.

\section{Serratus Anterior Stretch}

The subject was positioned on their side, lying with the shoulder undergoing the intervention positioned up, while the subject was instructed to relax. The therapist positioned himself in front of the subject and stabilized the subject's arm in his/her axilla and placed the thumb of the other hand horizontally on the SA under the scapula and in contact with the costal surface. The maneuverer may not be comfortable, and the thumb is pushed as far as the subject can tolerate. The maneuver attempts to separate the scapula from the ribs. Once the thumb sinks in under the scapula, the subject is asked to take a deep breath and hold it for at least 8 to 10 seconds. Each stretch lasts for 30 seconds. Three deep breaths are taken for a single stretch of 30 seconds. Three stretches are administered with an interval of 2 minutes in between. The thumb placement is shown in Figure 1.

Two physiotherapists, male and female with 3 years of experience, received training in this maneuver and administered it to the subjects of this trial.

\section{Data Analyses}

Descriptive statistics were computed for all variables. The mean and SD of the pretest scores, posttest scores, and the mean change in between each of the dependent variables was calculated. A paired $t$ test was used to analyze the pretest and posttest data for each variable. An independent sample $t$ test was used for the analysis of the baseline characteristics between the male and female subjects. The percentage change from the initial scores was calculated to show the amount of improvement in addition to the significant value. The effect size was calculated for each variable, as the sample size appeared small. Normal distribution of data $(P>.05)$ was assumed through the Shapiro-Wilk test.

\section{Results}

Measurements from all 30 subjects ( 15 males and 15 females) were collected before and after the intervention. The differences in the mean shoulder ROM variables before the intervention between males and females were not significant $(P>.05)$. The mean age (SD) for males and females was 21.13 (1.50) and 21.27 (1.87), respectively, with a $P$ value of .83 . The mean (SD) body mass index of the subjects was $22.30(3.38) \mathrm{kg} / \mathrm{m}^{2}$. The body mass index for males was 22.41 (3.63) and females was 22.18 (3.22), and the difference between the two was not significant $(P=.931)$. The

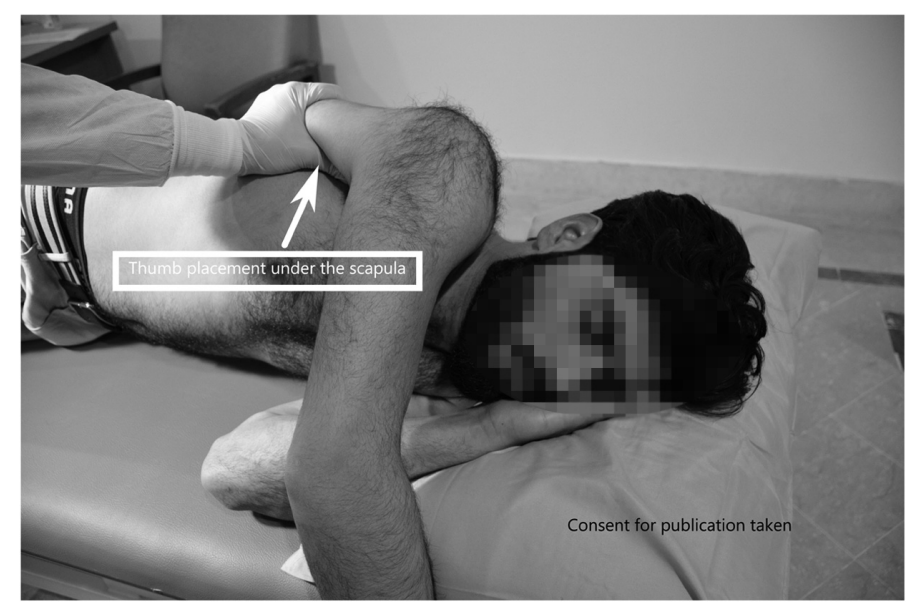

Figure 1 - Showing thumb placement for serratus anterior muscle under the scapula. 
Table 1 Range of Motion of Shoulder Before and After SAS

\begin{tabular}{|c|c|c|c|c|c|c|}
\hline Range of motion & $\begin{array}{c}\text { Preintervention } \\
\text { mean }^{0} \\
\overline{\boldsymbol{X}}^{0}\left(\mathrm{SD}^{0}\right)\end{array}$ & $\begin{array}{c}\text { Postintervention } \\
\bar{X}^{0} \\
\operatorname{mean}^{0}\left(S D^{0}\right)\end{array}$ & $\begin{array}{c}\text { Mean } \\
\text { change } \\
\Delta \bar{X}^{0}\left(S D^{0}\right)\end{array}$ & $\begin{array}{l}\text { Percentage } \\
\text { improvement }\end{array}$ & $\begin{array}{c}P \\
\text { value }\end{array}$ & $\begin{array}{c}\text { Cohen } d \\
\text { values }\end{array}$ \\
\hline Shoulder abduction & $153.50(17.82)$ & $167.00(17.10)$ & $13.50(11.82)$ & $8.7 \%$ & $<.000$ & 1.13 \\
\hline Shoulder flexion & $146.33(21.00)$ & $166.33(18.75)$ & $20.00(13.33)$ & $13.66 \%$ & $<.000$ & 1.50 \\
\hline $\begin{array}{l}\text { Shoulder internal } \\
\text { rotation }\end{array}$ & $55.17(12.42)$ & $61.167(11.35)$ & $6.00(7.47)$ & $10.87 \%$ & $<.000$ & 0.80 \\
\hline $\begin{array}{l}\text { Shoulder external } \\
\text { rotation }\end{array}$ & $46.33(11.81)$ & $52.00(14.53)$ & $5.66(9.35)$ & $12.16 \%$ & $<.002$ & 0.60 \\
\hline Total rotation & $102.17(21.20)$ & $113.17(23.58)$ & $11.00(14.22)$ & $10.76 \%$ & $<.000$ & 0.77 \\
\hline Hand behind back, $\mathrm{cm}$ & $20.85(2.62)$ & $15.78(2.89)$ & $5.10(2.21)$ & $24.48 \%$ & $<.000$ & 1.17 \\
\hline Hand behind neck, $\mathrm{cm}$ & $23.75(3.88)$ & $18.34(4.22)$ & $5.41(2.89)$ & $22.78 \%$ & $<.000$ & 1.86 \\
\hline
\end{tabular}

Abbreviation: SAS, serratus anterior stretch.

baseline scores of flexion, adduction, internal rotation, and external rotation showed limitation in comparison with the normative scores more in males than females, but the difference was not a significant difference between the 2 genders $(P>.05)$. All the scores changed significantly $(P=.00)$ from the baseline after the application of the SAS. A significant and pronounced improvement was noted in RUBTB and RDBTN. Significant $(P=.00)$ improvement was also noted in the rotatory motion of the shoulder, but the change was less pronounced than other ROM. The effect size was calculated by dividing the mean change through their respective SDs in all of the ranges, and a very large effect of more than 1 was found. Table 1 shows detailed statistics of the paired $t$ test.

\section{Discussion}

The purpose of this study was to evaluate the effectiveness of an SAS through improvement in the shoulder range of motion. The results of this study show the the novel SAS can effectively and acutely improve the shoulder range of motion in healthy subjects with restricted shoulder mobility. The most marked improvement is in the functional movements of RUBTB and RDBTN, which suggests that the stretch helps to improve mobility of the scapula by improving the flexibility of the lower and middle division of SA. Both these functional movements sum up the shoulder ROM of multiple planes. The improvement in flexibility due to the SAS conforms to the recommendation of Cools et $\mathrm{al},{ }^{8}$ who concluded that lack of flexibility and dysfunction of the SA and lower trapezius are the main concerns in the clinical management of scapular dysfunction.

The single session of SAS achieved a mean (SD) of flexion and abduction of $166.33^{\circ}\left(18.75^{\circ}\right)$ and $167.00^{\circ}\left(17.10^{\circ}\right)$, respectively. The normative values for the same are reported as $158.9^{\circ}\left(9.09^{\circ}\right)$ and $160.8^{\circ}\left(13.00^{\circ}\right)$ for the age group $20-49 .{ }^{15}$ The greater than normal range in these ROM was probably due to the younger age of the participants of this study. Internal rotation and external rotation improved with the SAS but failed to achieve the normative ranges since SA is not directly involved in these movements. A study on the acute effects of scapular mobilization, and with a small number of participants who had shoulder pathology, reported improvement in flexion and abduction, but it was less pronounced in comparison with the current study. ${ }^{3}$ Pain in these conditions might have been a confounding factor.
The sample size at the baseline was balanced with respect to gender, body mass index, and the baseline score of the ROM, as there was no significant difference and the improvement appeared to be true for the younger age group. The SAS may have a role in the prevention as well as rehabilitation of shoulder pathologies. The subjects in the current study were healthy young individuals and acute effects on shoulder ROM were measured. A trial of SAS on subjects with shoulder pathology is recommended, as shoulder pathology is not only associated with restricted range of motion, but also pain and strength deficits in multiple muscle groups.

A digital inclinometer (clinometer) installed on a smartphone is a better alternative to a conventional goniometer and inclinometer and is more sensitive to recording a change in the range of motion, as reported previously. ${ }^{14}$ The enumerator encountered no problem in recording all the shoulder ROM during the data collection.

The SA is more active in overhead movements beyond $120^{\circ}$, and a greater range of flexion and abduction translates into better reach of the hand down behind the neck, which is an important functional movement. The simultaneous improvement in overhead movement and RDBTN suggests increased scapular mobility and control via improved function of the SA. The greater improvement in RUBTB suggests an improvement in scapular protraction via lengthening and relaxation.

One of the major limitations of this study is the lack of a comparative group. Future studies should, therefore, compare SAS with other forms of stretches used for improving shoulder mobility.

\section{Conclusion and Recommendation}

An acute SAS intervention improves shoulder mobility in healthy individuals. It is recommended for the trial on the prevention and rehabilitation of shoulder pathologies with restriction in shoulder mobility.

\section{Acknowledgments}

The authors of this study are grateful to Aisling Gaughran for proofreading this manuscript. The authors also appreciate the efforts and time of the students and physiotherapists of the Helping Hand Institute of Rehabilitation Sciences during the collection of data and administration of the intervention. The authors declare no conflict of interest. 


\section{References}

1. Rockwood CA Jr, Wirth MA, Fehringer EV, Sperling JW. Rockwood and Matsen's The Shoulder E-Book. Philadelphia, PA: Elsevier Health Sciences; 2016.

2. Ekstrom RA, Bifulco KM, Lopau CJ, Andersen CF, Gough JR. Comparing the function of the upper and lower parts of the serratus anterior muscle using surface electromyography. J Orthop Sport Phys. 2004;34(5):235-243. PubMed ID: 15189015 doi:10.2519/ jospt.2004.34.5.235

3. Surenkok O, Aytar A, Baltaci G. Acute effects of scapular mobilization in shoulder dysfunction: a double-blind randomized placebocontrolled trial. J Sport Rehabil. 2009;18(4):493-501. PubMed ID: 20108851 doi:10.1123/jsr.18.4.493

4. Uhl TL, Kibler WB, Gecewich B, Tripp BL. Evaluation of clinical assessment methods for scapular dyskinesis. Arthroscopy. 2009;25(11): 1240-1248. PubMed ID: 19896045 doi:10.1016/j.arthro.2009.06.007

5. Lee J-H, Cynn H-S, Yi C-H, Kwon O-y, Yoon T-L. Predictor variables for forward scapular posture including posterior shoulder tightness. J Bodyw Mov Ther. 2015;19(2):253-260. PubMed ID: 25892380 doi:10.1016/j.jbmt.2014.04.010

6. Clarsen B, Bahr R, Andersson SH, Munk R, Myklebust G. Reduced glenohumeral rotation, external rotation weakness and scapular dyskinesis are risk factors for shoulder injuries among elite male handball players: a prospective cohort study. Br J Sports Med. 2014;48(17): 1327-1333. PubMed ID: 24948083 doi:10.1136/bjsports-2014093702

7. Andersen $\mathrm{CH}$, Zebis MK, Saervoll C, et al. Scapular muscle activity from selected strengthening exercises performed at low and high intensities. J Strenght Cond Res. 2012;26(9):2408-2416. PubMed ID: 22076101 doi:10.1519/JSC.0b013e31823f8d24

8. Cools AM, Struyf F, De Mey K, Maenhout A, Castelein B, Cagnie B. Rehabilitation of scapular dyskinesis: from the office worker to the elite overhead athlete. Br J Sport Med. 2014;48(8):692-697. PubMed ID: 23687006 doi:10.1136/bjsports-2013-092148

9. Keramat UK. Conservative treatment preferences and the plausible mechanism of Neer's stage 1 of shoulder impingement in younger people. J Pak Med Assoc. 2015;65(5):542-547. PubMed ID: 26028390

10. Tejera-Falcón E, del Carmen Toledo-Martel N, Sosa-Medina FM, et al. Dry needling in a manual physiotherapy and therapeutic exercise protocol for patients with chronic mechanical shoulder pain of unspecific origin: a protocol for a randomized control trial. $B M C$ Musculoskelet Disord. 2017;18(1):400. PubMed ID: 28923050 doi:10.1186/s12891-017-1746-3

11. Cook G, Burton L, Hoogenboom BJ, Voight M. Functional movement screening: the use of fundamental movements as an assessment of function-part 2. Int J Sports Phys. 2014;9(4):549-563. PubMed ID: 25133083

12. Bonazza NA, Smuin D, Onks CA, Silvis ML, Dhawan A. Reliability, validity, and injury predictive value of the functional movement screen: a systematic review and meta-analysis. Am J Sports Med. 2017;45(3):725-732. PubMed ID: 27159297 doi:10.1177/0363546 516641937

13. Smith AB. Validation of a smartphone application for measuring shoulder internal rotation and external rotation range of motion with intra-rater reliability. J Sports Med Allied Health Sci. 2016;2(1):11. doi:10.25035/jsmahs.02.01.11

14. Boissy P, Diop-Fallou S, Lebel K, Bernier M, Balg F, TousignantLaflamme Y. Trueness and minimal detectable change of smartphone inclinometer measurements of shoulder range of motion. Telemed $E$ Health. 2017;23(6):503-506. PubMed ID: 27911652 doi:10.1089/ tmj. 2016.0205

15. Gill H, Gustafsson L, Hawcroft L, McKenna K. Shoulder joint range of motion in healthy adults aged 20 to 49 years. Brit J Occup Ther. 2006;69(12):556-561. doi:10.1177/030802260606901204 